\title{
Seizures in supratentorial meningioma: a systematic review and meta-analysis
}

\author{
Dario J. Englot, MD, PhD, Stephen T. Magill, MD, PhD, Seunggu J. Han, MD, Edward F. Chang, MD, \\ Mitchel S. Berger, MD, and Michael W. McDermott, MD
}

Department of Neurological Surgery, University of California, San Francisco, California

\begin{abstract}
OBJECTIVE Meningioma is the most common benign intracranial tumor, and patients with supratentorial meningioma frequently suffer from seizures. The rates and predictors of seizures in patients with meningioma have been significantly under-studied, even in comparison with other brain tumor types. Improved strategies for the prediction, treatment, and prevention of seizures in patients with meningioma is an important goal, because tumor-related epilepsy significantly impacts patient quality of life.
\end{abstract}

METHODS The authors performed a systematic review of PubMed for manuscripts published between January 1980 and September 2014, examining rates of pre- and postoperative seizures in supratentorial meningioma, and evaluating potential predictors of seizures with separate meta-analyses.

RESULTS The authors identified 39 observational case series for inclusion in the study, but no controlled trials. Preoperative seizures were observed in $29.2 \%$ of 4709 patients with supratentorial meningioma, and were significantly predicted by male sex (OR 1.74, 95\% $\mathrm{Cl} 1.30-2.34$ ); an absence of headache (OR 1.77, 95\% $\mathrm{Cl} 1.04-3.25$ ); peritumoral edema (OR 7.48, 95\% Cl 6.13-9.47); and non-skull base location (OR 1.77, 95\% Cl 1.04-3.25). After surgery, seizure freedom was achieved in $69.3 \%$ of 703 patients with preoperative epilepsy, and was more than twice as likely in those without peritumoral edema, although an insufficient number of studies were available for formal meta-analysis of this association. Of 1085 individuals without preoperative epilepsy who underwent resection, new postoperative seizures were seen in $12.3 \%$ of patients. No difference in the rate of new postoperative seizures was observed with or without perioperative prophylactic anticonvulsants.

CONCLUSIONS Seizures are common in supratentorial meningioma, particularly in tumors associated with brain edema, and seizure freedom is a critical treatment goal. Favorable seizure control can be achieved with resection, but evidence does not support routine use of prophylactic anticonvulsants in patients without seizures. Limitations associated with systematic review and meta-analysis should be considered when interpreting these results.

http://thejns.org/doi/abs/10.3171/2015.4.JNS142742

KEY WORDS epilepsy; meningioma; predictor; seizure; surgery; oncology

$\mathrm{M}$ ENINGIOMA is the most common benign intracranial tumor, accounting for approximately onethird of all CNS tumors. ${ }^{66}$ Seizures are common in patients with supratentorial meningioma, affecting anywhere from $10 \%$ to $50 \%$ of individuals with these lesions, and they are frequently the presenting symptom. ${ }^{8,69} \mathrm{Re}$ current seizures in patients with brain tumors lead to significant morbidity, cognitive problems, inability to drive, and diminished quality of life. ${ }^{16,54,61}$ Also, antiepileptic drugs (AEDs) may have unfavorable neurocognitive side effects, and can fail to completely stop seizures in some individuals. ${ }^{2,10}$ In recent years, our group and others have helped characterize seizure predictors in the treatment of other intrinsic brain tumors, such as gliomas and glioneuronal tumors. ${ }^{7,14,15}$ However, rates, predictors, and control of seizures in meningioma have remained understudied and poorly understood, because most investigations focus on cytoreduction, alleviation of mass effect, and the 
prevention of neurological deficits. Given the deleterious effects of epilepsy on patient quality of life, an improved understanding of preoperative seizure risk factors and postoperative seizure outcomes is needed.

To our knowledge, only 4 studies in the past 35 years have directly examined both pre- and postoperative seizures in patients with meningioma, $, 5,8,37,51$ with another 5 manuscripts investigating various aspects of seizures after meningioma resection. ${ }^{9,18,53,62,69}$ Nevertheless, several studies examining other aspects of meningioma surgery, such as predictors of growth and extent of resection, also report data regarding seizure rates and associated factors. Thus, a significant amount of information regarding seizure predictors in patients with meningioma is present in the existing literature, although it has not yet been compiled or methodically reviewed.

In the present study, we performed the first systematic review of seizure rates and predictors in patients with supratentorial meningioma. We examined the published literature for factors associated with both pre- and postoperative seizures with these lesions, and further analyzed associated variables with formal meta-analyses. Our goals included improved prediction of which meningiomas harbor epileptogenicity and a better understanding of seizure outcomes in meningioma surgery, and we readdressed the question of whether prophylactic perioperative AEDs are warranted in patients without epilepsy.

\section{Methods}

\section{Article Selection and Data Extraction}

We performed a PubMed query for articles published between January 1980 and September 2014 with the search terms "meningioma AND seizure" or "meningioma AND epilepsy." Initially, 730 manuscripts were returned and evaluated for potential inclusion. References from reviewed manuscripts were examined for other potential studies for inclusion. Inclusion required primary clinical data regarding the incidence of preoperative and/ or postoperative seizures in patients with supratentorial meningioma. To control data quality, only peer-reviewed, published manuscripts were included, and meeting abstracts and presentations were not considered. The process of manuscript selection, including exclusion criteria, is illustrated in Fig. 1.

In total, 39 manuscripts met both inclusion and exclusion criteria, including 33 papers with data regarding preoperative seizures, and 18 studies with postoperative seizure data (12 manuscripts included data regarding both pre- and postoperative seizures). For seizure outcomes after tumor resection in patients with preoperative seizures, a minimum of 6 months of postoperative follow-up was required, and outcomes were evaluated using a modified Engel classification system. ${ }^{13}$ Patient data were stratified according to the following variables, where disaggregation in relationship to preoperative and/or postoperative seizure status was possible: age, sex, tumor hemisphere and location, presence of headache or neurological deficit, tumor size, presence or absence of peritumoral edema on neuroimaging, and WHO histopathological classification of tumor grade. In addition to these factors, patients in-
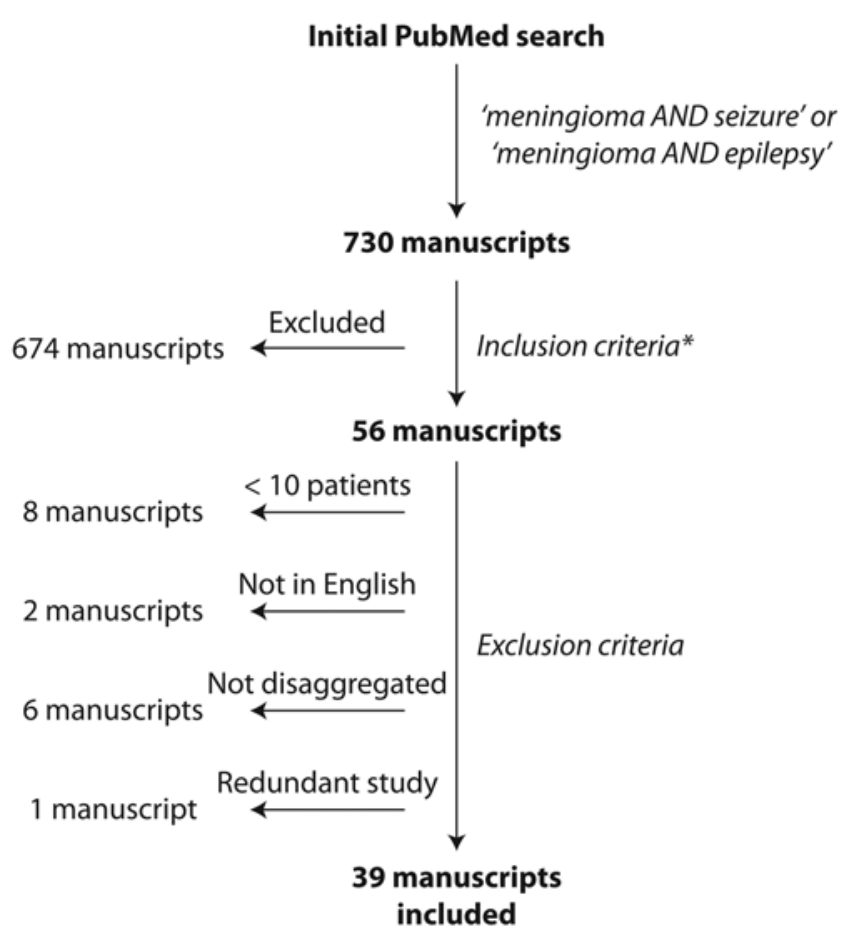

FIG. 1. Flowchart summarizing the manuscript selection process. Inclusion criteria $\left(^{*}\right)$ required manuscripts with primary clinical data regarding the incidence of preoperative and/or postoperative seizures in patients with supratentorial meningioma. Exclusion criteria included studies reporting data on < 10 patients, language other than English, insufficient disaggregation to determine precise seizure rates, or data redundant with another manuscript. Overall, 39 manuscripts met both inclusion and exclusion criteria.

cluded in postoperative seizure analysis were also evaluated for seizure type, history of previous radiation treatment for the meningioma, extent of tumor resection, evidence of postoperative tumor progression, and the use of AED prophylaxis (at least 3 days in the perioperative period) in patients without preoperative seizures. For the purposes of this study, extent of resection was considered gross-total for Simpson Grade 1-3 resection and subtotal for Simpson Grade 4-5 removal. ${ }^{57}$ This study was prepared according to the Preferred Reporting Items for Systematic Reviews and Meta-Analyses (PRISMA) statement. ${ }^{42}$

\section{Statistical Analysis}

Rates of pre- and postoperative seizures were calculated across all patients and stratified by various factors of interest. For summary purposes, initial between-group comparisons were performed using Pearson's chi-square tests. Variables found to be potentially associated with pre- or postoperative seizures on initial review $(p<0.05)$ were dichotomized and analyzed with separate metaanalyses. To limit selection bias, meta-analysis was only performed on a variable if data regarding that variable were available from at least 5 different manuscripts and across at least 2 separate conditions. As an example, although more than 5 manuscripts reported data regarding patient age, fewer than 5 of these studies contained patients from both conditions (pediatric and adult) in the 
same study, so the potential effect of pediatric versus adult age group on seizure status could not be formally metaanalyzed. For each meta-analysis, heterogeneity across the studies was evaluated using the Cochran Q statistic, and a fixed-effects model was used to generate a pooled proportion. Individual studies were weighted using the inverse variance method, and between-group hypothesis testing was performed on the calculated odds ratio of the pooled proportions. Forest plots were generated to express effect size across all studies for each variable. Odds ratios were calculated with a $95 \%$ confidence interval. The Friedman and Kendall W tests were used to test data heterogeneity between studies to ensure that a fixed-effects model was appropriate. The possible effect of publication bias was assessed using funnel plots. Statistical analysis was performed using SPSS version 20 (SPSS, Inc.) with significance assessed at $\mathrm{p}<0.05$.

\section{Results}

Thirty-nine studies reporting seizure rates and associated factors in patients with supratentorial meningiomas

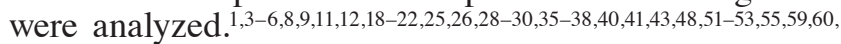
62-64,68-70 All investigations were retrospective observational case series, and no prospective controlled trials were identified.

Preoperative seizures were examined across 33 manuscripts including 4709 patients (63\% female), with $10-946$ patients per report (Table 1). Although most investigations included only adult patients, several studies of pediatric meningioma were also identified, and some manuscripts included mixed age populations. Overall, seizures were observed in $29.2 \%$ of patients with supratentorial meningioma, with rates varying between $12 \%$ and $76 \%$ across individual studies.

Several factors were evaluated for a potential relationship with preoperative seizures, where data were available (Table 2). Of the 33 studies examined, 9 manuscripts (27\%) contained data for $>75 \%$ of the variables of interest, whereas 6 studies (18\%) included data for $<25 \%$ of the factors examined. Seizures were more common among males compared with females, in adults versus children and adolescents, and in patients with peritumoral edema or without headaches compared with their counterparts. Among common tumor locations, seizure rates were higher with parasagittal or convexity tumors, and lower with skull base lesions. No significant difference in seizure incidence was seen with tumor side, size, or pathological grade, or with the presence or absence of neurological deficit.

Formal meta-analyses were then performed to evaluate each of 5 potential predictors of preoperative seizures (Fig. 2), with the exception of age, given that fewer than 5 manuscripts included disaggregated data for both adult and pediatric patients in the same study. We observed that seizures were significantly more common in males versus females (OR 1.74, 95\% CI 1.30-2.34) (Fig. 2A), and in patients without a history of headache, compared with those with headaches (OR 1.77, 95\% CI 1.04-3.25) (Fig. 2B). The presence of peritumoral edema on neuroimaging was the strongest predictor of seizures, with an OR of 7.48 (95\% CI 6.13-9.47) (Fig. 2C). Finally, meningiomas not
TABLE 1. Incidence of preoperative seizures in patients with supratentorial meningioma

\begin{tabular}{|c|c|c|c|c|}
\hline Study & No. & $\begin{array}{l}\text { Age } \\
\text { Group }\end{array}$ & $\begin{array}{c}\% \\
\text { Female }\end{array}$ & $\begin{array}{c}\% \text { w/ } \\
\text { Seizures }\end{array}$ \\
\hline Chaichana et al., 2013 & 626 & Adult & 62.9 & 13.4 \\
\hline Ravindranath et al., 2013 & 31 & Pediatric & 29.0 & 35.5 \\
\hline Zheng et al., 2013 & 946 & Adult & NS & 15.2 \\
\hline Musluman et al., 2012 & 42 & Adult & 57.1 & 23.8 \\
\hline Waagemans et al., 2011 & 89 & Adult & 74.2 & 12.4 \\
\hline Zachenhofer et al., 2011 & 16 & Adult & NS & 31.3 \\
\hline Sughrue et al., 2010 & 15 & Adult & 60.0 & 40.0 \\
\hline Dijkstra et al., 2009 & 89 & Adult & 74.2 & 33.7 \\
\hline Li \& Zhao, 2009 & 27 & Pediatric & NS & 22.2 \\
\hline Menon et al., 2009 & 38 & Pediatric & 47.4 & 76.3 \\
\hline Behari et al., 2008 & 20 & Adult & 50.0 & 35.0 \\
\hline Gazzeri et al., 2008 & 36 & Adult & 66.7 & 27.8 \\
\hline Rushing et al., 2005 & 87 & Pediatric & 40.2 & 33.3 \\
\hline Rothoerl et al., 2003 & 102 & Adult & 72.5 & 31.4 \\
\hline Tucha et al., 2003 & 54 & Adult & 68.5 & 35.2 \\
\hline Zwerdling \& Dothage, 2002 & 17 & Pediatric & 58.8 & 29.4 \\
\hline Im et al., 2001 & 10 & Pediatric & 50.0 & 50.0 \\
\hline Amirjamshidi et al., 2000 & 24 & Pediatric & 54.2 & 20.8 \\
\hline Lieu \& Howng, 2000 & 201 & Mixed & 67.0 & 28.4 \\
\hline Chozick et al., 1996 & 158 & Adult & 68.4 & 39.9 \\
\hline Lobato et al., 1996 & 400 & Mixed & 70.5 & 38.8 \\
\hline Meixensberger et al., 1996 & 385 & Adult & 66.8 & 21.0 \\
\hline Kawaguchi et al., 1996 & 83 & Adult & 69.9 & 32.5 \\
\hline Chow et al., 1995 & 285 & Mixed & 62.0 & 33.7 \\
\hline Germano et al., 1994 & 23 & Pediatric & 39.1 & 26.1 \\
\hline Kilpatrick et al., 1994 & 29 & Adult & 69.0 & 51.7 \\
\hline de Vries \& Wakhloo, 1993 & 51 & NS & NS & 39.2 \\
\hline Tsuji et al., 1993 & 17 & Adult & 64.7 & 17.6 \\
\hline Howng \& Kwan, 1992 & 83 & Mixed & 66.3 & 65.1 \\
\hline Ferrante et al., 1989 & 19 & Pediatric & 31.6 & 31.6 \\
\hline Chan \& Thompson, 1984 & 237 & Mixed & 67.5 & 42.6 \\
\hline Giombini et al., 1984 & 342 & NS & 55.6 & 60.5 \\
\hline Ramamurthi et al., 1980 & 127 & NS & 39.4 & 29.1 \\
\hline Total & 4709 & & 63.0 & 29.2 \\
\hline
\end{tabular}

NS $=$ not specified.

located at the skull base were significantly more likely to cause seizures than skull base tumors (OR 1.77 95\% CI 1.04-3.25) (Fig. 2D).

We then evaluated the rates of postoperative seizures after meningioma resection in patients with or without seizures before surgery. Seizure outcomes in patients with preoperative seizures were available from 14 studies of 703 patients, including between 5 and 101 individuals per study (Table 3). Overall, 69.3\% achieved seizure freedom (Engel Grade I outcome) after tumor resection, whereas $30.7 \%$ of these individuals experienced persistent seizures (Engel Grades II-IV outcome). Fourteen manuscripts reported rates of new postoperative seizures across 1085 in- 
TABLE 2. Factors associated with preoperative seizures in patients with supratentorial meningioma

\begin{tabular}{|c|c|c|c|c|}
\hline Factor & Seizures & No Seizures & $p$ Value & Included Studies \\
\hline Sex & & & $<0.001^{*}$ & $1,4,5,8,19,21,26,29,37,59,62,70$ \\
\hline Female & $174(19.3)$ & $727(80.7)$ & & \\
\hline Male & $137(31.0)$ & $305(69.0)$ & & \\
\hline Age & & & $<0.001^{*}$ & $\begin{array}{l}1,4,5,9,12,19,20,26,29,30,36,37,40,41,43,53,55,59 \\
\quad 62-64,68,70\end{array}$ \\
\hline$<18$ yrs & $92(41.6)$ & $129(58.4)$ & & \\
\hline$\geq 18$ yrs & $466(23.7)$ & $1500(76.3)$ & & \\
\hline Side & & & 0.24 & $1,4,19,37,59,62,63,70$ \\
\hline $\mathrm{Lt}$ & $51(34.7)$ & $96(65.3)$ & & \\
\hline Rt & $52(31.3)$ & $114(68.7)$ & & \\
\hline Midline/bilat & $6(26.1)$ & $17(73.9)$ & & \\
\hline Headache & & & $0.03^{*}$ & $4,5,26,59,70$ \\
\hline Yes & $35(11.9)$ & $258(88.1)$ & & \\
\hline No & $72(18.2)$ & $323(81.8)$ & & \\
\hline Neurological deficit & & & 0.91 & $1,4,5,19,59,70$ \\
\hline Yes & $36(15.4)$ & $198(84.6)$ & & \\
\hline No & $78(16.0)$ & $408(84.0)$ & & \\
\hline Peritumoral edema & & & $<0.001^{*}$ & $4,5,11,25,26,29,37,62$ \\
\hline Yes & $145(37.5)$ & $242(62.5)$ & & \\
\hline No & $113(16.0)$ & $595(84.0)$ & & \\
\hline Pathology & & & 0.10 & $1,4,5,8,11,12,19,26,29,37,59,64,70$ \\
\hline WHOI & $342(23.1)$ & $1136(76.9)$ & & \\
\hline WHO II-III & $18(33.3)$ & $36(66.7)$ & & \\
\hline Location & & & $<0.001^{*}$ & $1,4,5,8,9,19,20,22,26,37,43,62,70$ \\
\hline Convexity & $153(31.7)$ & $329(68.3)$ & & \\
\hline Parasagittal/falx & $287(45.4)$ & $345(54.6)$ & & \\
\hline Sphenoid wing & $67(24.7)$ & $204(75.3)$ & & \\
\hline Olfactory groove & $35(24.5)$ & $108(75.5)$ & & \\
\hline Planum/tuberculum & $5(3.4)$ & $143(96.6)$ & & \\
\hline Tentorial & $0(0)$ & $34(100)$ & & \\
\hline Intraventricular & $2(8.3)$ & $22(91.7)$ & & \\
\hline Petroclival & $5(45.5)$ & $6(54.5)$ & & \\
\hline Size & & & 0.73 & $4,26,29,59,62$ \\
\hline$\leq 4 \mathrm{~cm}$ & $26(31.0)$ & $58(69.0)$ & & \\
\hline$>4 \mathrm{~cm}$ & $22(33.8)$ & $43(66.2)$ & & \\
\hline
\end{tabular}

dividuals without a history of seizures, with study sizes ranging from 11 to 180 patients (Table 4). Overall, $12.3 \%$ of these patients had new epileptic events after resection.

Factors associated with postoperative seizures were then examined in patients with or without preoperative seizures (Table 5). Of the 23 studies examined, 5 investigations $(22 \%)$ included data for $>75 \%$ of the variables of interest, whereas 3 manuscripts (13\%) included data for $<25 \%$ of the factors examined. Among patients with preoperative seizures, a strong association was observed between persistent postoperative seizures and peritumoral edema. Across tumor locations, persistent seizures were most common with sphenoid wing and parasagittal lesions. Also, tumor progression after surgery was associ- ated with seizure recurrence. Among patients without preoperative seizures, new postoperative seizures were more common in those with a history of previous radiation, and in individuals with gross-total resection. However, the total number of patients with new seizures in each of these categories was low (9-11 patients), limiting the ability to draw conclusions. Of note, the rates of new postoperative seizures were similar between individuals who did or did not receive perioperative AED prophylaxis, with this analysis restricted to patients without preoperative seizures. No relationship was observed between postoperative seizures and other variables interrogated.

Meta-analysis of tumor location revealed that postoperative seizures were somewhat less common with 

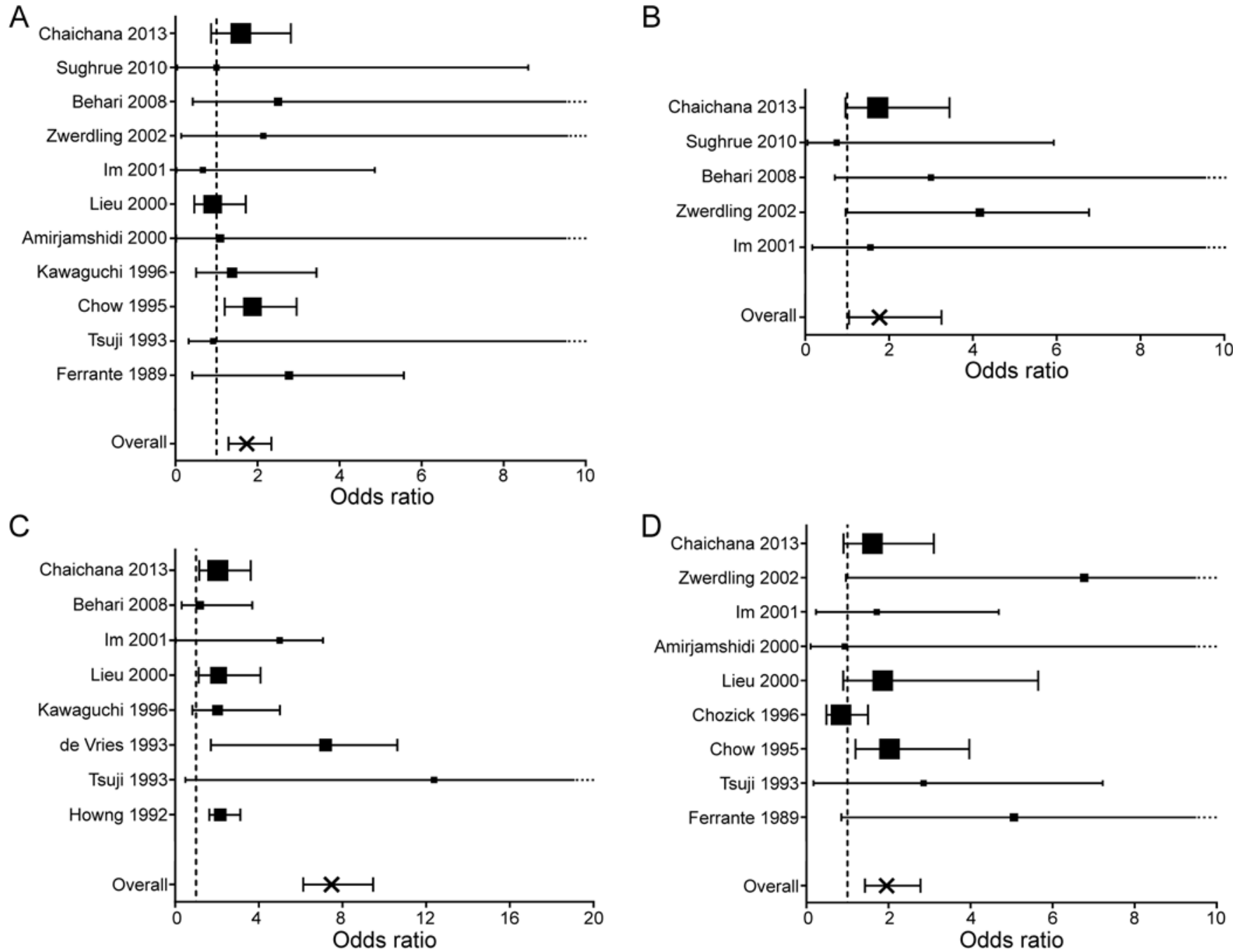

FIG. 2. Meta-analyses examining factors associated with preoperative seizures in supratentorial meningioma. Statistically significant predictors of postoperative seizure freedom included male (vs female) sex (A); absence (vs. presence) of headache (B); the presence of peritumoral edema on neuroimaging (vs. no or minimal edema) (C); and skull base (vs. non-skull base) tumor location (D). The effect size for each study is represented as the OR of factors associated with preoperative seizures (larger OR indicates greater likelihood of seizures), with proportional study weight estimated by the size of each point. Error bars represent the $95 \%$ $\mathrm{Cl}$, with a dotted tail indicating an upper limit off of the scale. The size of each point estimates proportional study weight, and the vertical dashed line represents OR $=1$.

skull bases meningiomas than non-skull base lesions, although this difference was not significant (OR $0.85,95 \%$ CI 0.45-1.46) (Fig. 3). Finally, sufficient data for formal meta-analysis (at least 2 conditions from 5 manuscripts) were not available to further examine the relationship between other factors, such as peritumoral edema or tumor progression, and postoperative seizures.

\section{Discussion}

In the present study, we report the first systematic review and meta-analysis of both pre- and postoperative seizures in patients with meningioma, including data from 39 studies. Overall, preoperative seizures were present in $29.2 \%$ of 4709 patients with supratentorial meningioma. After resection, seizure freedom was achieved in 69.3\% of 703 individuals with seizures before surgery, and new epileptic events were observed in $12.3 \%$ of 1085 patients without preoperative epilepsy. Several factors were found to be associated with tumor-related seizures, allowing insight into seizure prediction, treatment, and prevention in supratentorial meningioma.

The rates of both pre- and postoperative seizures were more than double in patients with peritumoral edema than in individuals without this neuroimaging finding. Brain edema is found in between one-third to two-thirds of intracranial meningiomas, and several previous studies have observed a relationship between edema and epilepsy. ${ }^{5,11,29,37,38}$ Vasogenic peritumoral edema in meningioma is believed to be related to angiogenesis and increased pial blood supply, and has been associated with increased expression of vascular endothelial growth factor, metallo- 
TABLE 3. Seizure outcomes after meningioma resection in patients with preoperative seizures

\begin{tabular}{lrc}
\hline \multicolumn{1}{c}{ Study } & No. & \% Seizure Free \\
\hline Chaichana et al., 2013 & 64 & 87.5 \\
\hline Fang et al., 2013 & 91 & 81.3 \\
\hline Ravindranath et al., 2013 & 11 & 81.8 \\
\hline Zheng et al., 2013 & 97 & 66.0 \\
\hline Dijkstra et al., 2009 & 30 & 73.3 \\
\hline Gazzeri et al., 2008 & 10 & 90.0 \\
\hline Rothoerl et al., 2003 & 32 & 71.9 \\
\hline Zwerdling \& Dothage, 2002 & 5 & 40.0 \\
\hline Im et al., 2001 & 5 & 80.0 \\
\hline Lieu \& Howng, 2000 & 59 & 62.7 \\
\hline Chozick et al., 1996 & 63 & 63.5 \\
\hline Chow et al., 1995 & 98 & 67.3 \\
\hline Chan \& Thompson, 1984 & 101 & 60.4 \\
\hline Ramamurthi et al., 1980 & 37 & 54.1 \\
\hline Total & 703 & 69.3 \\
\hline
\end{tabular}

proteinases 2 and 9, and aquaporins 4 and 5.27,34,45-47,50,65,67 Two studies found edema to be most common with convexity or parasagittal meningiomas, ${ }^{11,38}$ but another did not observe a relationship to location, ${ }^{29}$ and no consistent association between edema and tumor size or pathological subtype is present across studies. . $^{11,29,38,49}$ Some groups have also suggested a relationship between brain invasion and edema, ${ }^{39,44}$ although it is unclear if edema resulting from tumor infiltration differs from vasogenic edema in meningiomas without invasion. ${ }^{31,39}$ Brain invasion was not investigated in our study, as these data were not reported in the source studies we examined. Given the relationship between angiogenesis and edema, further research may consider whether antiangiogenic agents that are being explored for meningioma therapy may also have antiepileptic effects.

Although meningiomas are more common in females and adults, our findings suggest that among patients with these lesions, males and children are more likely to suffer from preoperative seizures. Although the reasons for this are not fully understood, it is known that across all causes of epilepsy, the incidence is slightly higher in men than women and in children than in adults. ${ }^{33}$ Interestingly, preoperative seizures were also more common in patients without a history of headache in our study. One could speculate that headaches may lead to earlier discovery of these lesions before seizures develop, although this has not been previously established.

With regard to tumor location, we observed the highest rate of preoperative seizures in non-skull base lesions, such as parasagittal or convexity meningiomas. The propensity for convexity tumors to cause seizures has been previously described, ${ }^{37}$ and may be related to the extent of cortex affected by meningiomas in these locations, although tumor size itself was not identified as a risk factor in our study. Interestingly, the opposite trend was observed with postoperative seizures, which were much less com-
TABLE 4. Incidence of new postoperative seizures after meningioma resection in patients without preoperative seizures

\begin{tabular}{lrc}
\hline \multicolumn{1}{c}{ Study } & No. & \% w/ New Seizures \\
\hline Musluman et al., 2012 & 32 & 6.3 \\
\hline Sughrue et al., 2011 & 180 & 0.6 \\
\hline Zachenhofer et al., 2011 & 11 & 9.1 \\
\hline Jallo \& Benjamin, 2002 & 23 & 0.0 \\
\hline Zwerdling \& Dothage, 2002 & 12 & 0.0 \\
\hline Lieu \& Howng, 2000 & 163 & 18.4 \\
\hline Beenen et al., 1999 & 15 & 6.7 \\
\hline Chozick et al., 1996 & 95 & 8.4 \\
\hline Chow et al., 1995 & 225 & 17.3 \\
\hline Tsuji et al., 1993 & 14 & 14.3 \\
\hline Lee et al., 1989 & 50 & 2.0 \\
\hline Chan \& Thompson, 1984 & 156 & 18.6 \\
\hline North et al., 1983 & 19 & 21.1 \\
\hline Ramamurthi et al., 1980 & 90 & 16.7 \\
\hline Total & 1085 & 12.3 \\
\hline
\end{tabular}

mon in convexity lesions and more frequently observed with skull base tumors, such as those at the sphenoid wing. It is unknown if this distinction is influenced by surgical factors, such as greater use of brain retraction in skull base resections.

In patients without preoperative epilepsy, equivalent rates of new postoperative seizures were seen with or without the use of prophylactic anticonvulsants. Previous studies have also failed to demonstrate benefit with prophylactic AEDs in meningioma surgery. ${ }^{32,60}$ A randomized, controlled trial of valproic acid prophylaxis in all brain tumor surgery published in 1996 suggested that individuals receiving prophylaxis actually had a nonsignificantly increased rate of seizures compared with patients receiving placebo. ${ }^{24}$ Soon after, the American Academy of Neurology advised against long-term AED prophylaxis in patients with newly diagnosed brain tumor, ${ }^{23}$ and metaanalysis of the literature provided further evidence against the prophylactic use of antiseizure medications. ${ }^{58}$ Thus, evidence to date does not support the routine use of AED prophylaxis in meningioma surgery, although a potential role for short-term perioperative prophylaxis in select cases of high seizure risk, such as tumors with significant edema, deserves further exploration. It is also important to note that in the present study there was variability between prophylactic AED regimens used at different centers. In most cases, AEDs were first administered intraoperatively and continued for 3-7 days postoperatively (a minimum of 3 days of prophylaxis was required for inclusion). Also, although phenytoin was the most common agent used for prophylaxis, levetiracetam has become a more popular choice in more recent patient series. Limitations related to practice variability must be considered when interpreting the findings of the present study.

In epilepsy associated with other intrinsic brain tumors, such as gliomas or glioneuronal tumors, seizure freedom after surgery is predicted by gross-total resection. ${ }^{14,15,17} \mathrm{We}$ 
TABLE 5. Factors associated with postoperative seizures in patients with supratentorial meningioma

\begin{tabular}{|c|c|c|c|c|c|c|c|}
\hline \multirow[b]{2}{*}{ Factor } & \multicolumn{3}{|c|}{ Patients w/ Preop Seizures } & \multicolumn{3}{|c|}{ Patients w/o Preop Seizures } & \multirow[b]{2}{*}{ Included Studies } \\
\hline & $\begin{array}{l}\text { Persistent } \\
\text { Seizures }\end{array}$ & $\begin{array}{l}\text { Seizure } \\
\text { Free }\end{array}$ & p Value & New Seizures & $\begin{array}{l}\text { No New } \\
\text { Seizures }\end{array}$ & $p$ Value & \\
\hline Sex & & & 0.48 & & & 0.18 & $9,26,28,37,60,62,69,70$ \\
\hline Female & $68(26.8)$ & $186(73.2)$ & & $6(2.6)$ & $229(97.4)$ & & \\
\hline Male & $41(30.1)$ & $95(69.9)$ & & $5(5.6)$ & $84(94.4)$ & & \\
\hline Age & & & 0.99 & & & 0.99 & $\begin{array}{l}3,5,9,12,18,20,26,28,35,37,43,53,60 \\
\quad 62,68-70\end{array}$ \\
\hline$<18 \mathrm{yrs}$ & $1(20.0)$ & $4(80.0)$ & & $0(0.0)$ & $12(100.0)$ & & \\
\hline$\geq 18$ yrs & $149(24.4)$ & $461(75.6)$ & & $16(3.8)$ & $404(96.2)$ & & \\
\hline Side & & & 0.80 & NA & NA & & $26,28,37,62,69$ \\
\hline $\mathrm{Lt}$ & $46(25.3)$ & $136(74.7)$ & & & & & \\
\hline Rt & $38(28.1)$ & $97(71.9)$ & & & & & \\
\hline Midline/bilat & $1(20.0)$ & $4(80.0)$ & & & & & \\
\hline Neurological deficit & & & 0.57 & & & 0.43 & $9,69,70$ \\
\hline Yes & $16(39.0)$ & $25(61.0)$ & & $3(10.7)$ & $25(89.3)$ & & \\
\hline No & $40(33.6)$ & $79(66.4)$ & & $5(6.3)$ & $74(93.7)$ & & \\
\hline Peritumoral edema & & & $<0.001^{*}$ & & & 0.99 & $26,37,62$ \\
\hline Yes & $30(35.7)$ & $54(64.3)$ & & $1(20.0)$ & $4(80.0)$ & & \\
\hline No & $23(15.8)$ & $123(84.2)$ & & $1(11.1)$ & $8(88.9)$ & & \\
\hline Pathology & & & 0.22 & & & 0.42 & $5,9,12,18,26,37,60,70$ \\
\hline WHOI & $101(22.1)$ & $356(77.9)$ & & $6(2.7)$ & $217(97.3)$ & & \\
\hline WHO II-III & $6(37.5)$ & $10(62.5)$ & & $3(4.7)$ & $61(95.3)$ & & \\
\hline Location & & & $<0.05^{\star}$ & & & 0.22 & $9,20,26,28,37,43,60,62,69,70$ \\
\hline Convexity & $47(31.5)$ & $102(68.5)$ & & $8(3.3)$ & $234(96.7)$ & & \\
\hline Parasagittal/falx & $26(25.5)$ & $76(74.5)$ & & $1(33.3)$ & $2(66.7)$ & & \\
\hline Sphenoid wing & $18(45.0)$ & $22(55.0)$ & & $2(6.5)$ & $29(93.5)$ & & \\
\hline Olfactory groove & $5(17.9)$ & $23(82.1)$ & & $2(5.3)$ & $36(94.7)$ & & \\
\hline Planum/tuberculum & $5(17.9)$ & $23(82.1)$ & & $0(0.0)$ & $24(100.0)$ & & \\
\hline Tentorial & $0(0.0)$ & $0(0.0)$ & & $0(0.0)$ & $3(100.0)$ & & \\
\hline Intraventricular & $1(33.3)$ & $2(66.7)$ & & $0(0.0)$ & $1(100.0)$ & & \\
\hline Petroclival & $0(0.0)$ & $7(100.0)$ & & $0(0.0)$ & $3(100.0)$ & & \\
\hline Size & & & 0.99 & & & 0.16 & $26,28,62$ \\
\hline$\leq 4 \mathrm{~cm}$ & $0(0.0)$ & $3(100.0)$ & & $1(2.9)$ & 33 (97.1) & & \\
\hline$>4 \mathrm{~cm}$ & $1(20.0)$ & $4(80.0)$ & & $1(33.3)$ & $2(66.7)$ & & \\
\hline Seizure type & & & 0.14 & NA & NA & & $9,26,69$ \\
\hline Partial only & $21(28.4)$ & $53(71.6)$ & & & & & \\
\hline Generalized & $36(39.6)$ & $55(60.4)$ & & & & & \\
\hline Previous radiation & & & 0.29 & & & $<0.01^{*}$ & $9,26,60,69$ \\
\hline Yes & $8(47.1)$ & $9(52.9)$ & & $5(13.2)$ & $33(86.8)$ & & \\
\hline No & 49 (33.1) & $99(66.9)$ & & $4(1.7)$ & $233(98.3)$ & & \\
\hline AED prophylaxis & NA & NA & & & & 0.99 & $3,9,35,48,60,68$ \\
\hline Yes & & & & $55(13.7)$ & $346(86.3)$ & & \\
\hline No & & & & $17(13.2)$ & $112(86.8)$ & & \\
\hline Extent of resection & & & 0.18 & & & $0.02^{*}$ & $9,26,28,37,60,62,70$ \\
\hline Gross-total & $91(26.8)$ & $249(73.2)$ & & $6(2.2)$ & $268(97.8)$ & & \\
\hline Subtotal & $18(36.0)$ & $32(64.0)$ & & $5(10.0)$ & $45(90.0)$ & & \\
\hline Tumor progression & & & $<0.05^{\star}$ & & & $<0.05^{*}$ & 9,37 \\
\hline Yes & $25(38.5)$ & $40(61.5)$ & & $4(21.1)$ & $15(78.9)$ & & \\
\hline No & $83(26.2)$ & $234(73.8)$ & & $4(5.3)$ & $72(94.7)$ & & \\
\hline
\end{tabular}

$\mathrm{NA}=$ not available.

${ }^{*} p<0.05$, chi-square test. 


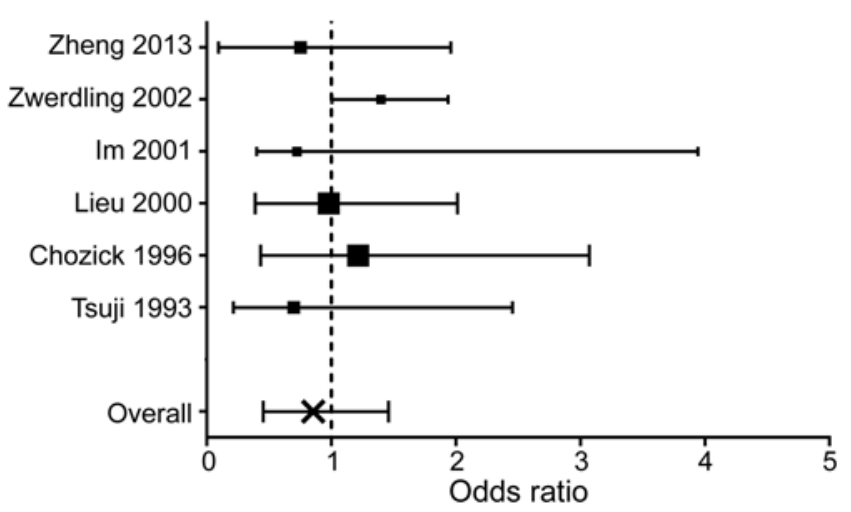

FIG. 3. Meta-analysis investigating the association between meningioma location and postoperative seizures. In examining the likelihood of postoperative seizures among skull base versus non-skull base meningiomas, no significant relationship between tumor location and seizures was observed. The effect size for each study is represented as the OR of factors associated with preoperative seizures (a larger OR indicates greater likelihood of seizures), with proportional study weight estimated by the size of each point. Error bars represent the $95 \% \mathrm{Cl}$. The size of each point estimates proportional study weight, and the vertical dashed line represents $\mathrm{OR}=1$.

did observe a trend between tumor regrowth and seizures after surgery, suggesting a relationship between cytoreduction and seizure freedom, which has also been reported by others. ${ }^{8,69}$ However, gross-total resection itself did not predict postoperative seizure freedom after surgery. Indeed, new postoperative seizures in patients without previous epilepsy were more common after gross-total resection, although the small number of patients with new seizures in this comparison limits our ability to draw clear conclusions. Also, it is unknown if new postoperative seizures may be related to greater brain manipulation with more aggressive resection. Notably, most studies demonstrating a connection between extent of resection and seizure outcome in glioma and glioneuronal tumors focus on patients with medically refractory epilepsy, whereas our study includes both patients with medically controlled and intractable seizures. Unfortunately, we identified only 1 study that specified the proportion of patients with medically refractory epilepsy ( $38 \%$ of 84 individuals with seizures), ${ }^{5}$ and no manuscripts disaggregated postoperative seizure outcome based on preoperative seizure control on AEDs. Improved characterization of seizure outcomes in meningioma patients with intractable epilepsy will be a critical goal for future studies, given the significant impact that seizure freedom has on quality of life in these individuals.

There are several other limitations of the present study that should be addressed, including inherent limitations in meta-analysis techniques that have been recently discussed by Sampson and Barker. ${ }^{56}$ A meta-analysis combines data from related studies to generate a larger number of patients, and thus enhance the ability to detect statistically reliable differences between comparison groups. However, the reliability of our results is dependent on the quality of data collected by others, and selection bias may influence the generalizability of our findings. Although high-quality meta-analysis requires a certain degree of homogeneity between studies, the potential heterogeneity in patient populations at various treatment centers must be considered. Although measures were used to optimize the selection of dependable source studies, all investigations performed on the topic of seizures in meningioma have been retrospective in nature, and are therefore susceptible to recall bias. Furthermore, there are probably interactions among variables associated with tumor-related seizuressuch as brain edema and tumor characteristics-but potential confounders could not be explored here, because the nature of meta-analysis precludes multivariate analysis.

We examined studies performed over a long period of time ( $<30$ years), which has the advantage of capturing a larger and more representative patient sample. However, while the natural course of meningioma and seizures has probably not changed over this time, diagnostic and surgical technologies certainly have. This must be considered in interpreting our results regarding postoperative seizures, although we did not observe any time-related trends in the associations we found. Despite these limitations, our study summarizes for the first time the rates and predictors of seizures in a very large sample size that would probably be otherwise unachievable, even with a multicenter prospective study. The present study demonstrates on a large scale that peritumoral edema is the strongest predictor of both pre- and postoperative seizures in meningioma, that favorable seizure outcomes are typically achieved with resection in patients who have seizures, and that perioperative anticonvulsant prophylaxis probably does not decrease the risk of new seizures in patients without epilepsy. In our clinical practice, these findings have led to decreased use of perioperative AED prophylaxis, except in patients with significant peritumoral edema on MRI.

\section{Conclusions}

Tumor-related epilepsy significantly impacts patient quality of life. Although seizures are very common in patients with supratentorial meningioma, the rates and predictors of seizures in this population have been significantly under-studied, even in comparison with other brain tumor types. In the first systematic review and meta-analysis to address this topic, we observed that approximately $30 \%$ of patients with meningioma suffer from seizures, and seizure freedom is achieved with resection in nearly $70 \%$ of those individuals. Peritumoral edema is the factor most strongly related to seizures, and differences are also seen based on patient demographics and tumor location. In patients without preoperative epilepsy, $12 \%$ experience new seizures after surgery, and this rate was not altered with the use of prophylactic AEDs. These results have important implications for seizure prediction, treatment, and prevention in patients with meningioma.

\section{Acknowledgments}

This work was supported in part by the NIH (F32-NS086353 to Dr. Englot).

\section{References}

1. Amirjamshidi A, Mehrazin M, Abbassioun K: Meningiomas of the central nervous system occurring below the age of 17 : 
report of 24 cases not associated with neurofibromatosis and review of literature. Childs Nerv Syst 16:406-416, 2000

2. Arzimanoglou A, Ben-Menachem E, Cramer J, Glauser T, Seeruthun R, Harrison M: The evolution of antiepileptic drug development and regulation. Epileptic Disord 12:3-15, 2010

3. Beenen LF, Lindeboom J, Kasteleijn-Nolst Trenité DG, Heimans JJ, Snoek FJ, Touw DJ, et al: Comparative double blind clinical trial of phenytoin and sodium valproate as anticonvulsant prophylaxis after craniotomy: efficacy, tolerability, and cognitive effects. J Neurol Neurosurg Psychiatry 67:474-480, 1999

4. Behari S, Giri PJ, Shukla D, Jain VK, Banerji D: Surgical strategies for giant medial sphenoid wing meningiomas: a new scoring system for predicting extent of resection. Acta Neurochir (Wien) 150:865-877, 2008

5. Chaichana KL, Pendleton C, Zaidi H, Olivi A, Weingart JD, Gallia GL, et al: Seizure control for patients undergoing meningioma surgery. World Neurosurg 79:515-524, 2013

6. Chan RC, Thompson GB: Morbidity, mortality, and quality of life following surgery for intracranial meningiomas. A retrospective study in 257 cases. J Neurosurg 60:52-60, 1984

7. Chang EF, Potts MB, Keles GE, Lamborn KR, Chang SM, Barbaro NM, et al: Seizure characteristics and control following resection in 332 patients with low-grade gliomas. J Neurosurg 108:227-235, 2008

8. Chow SY, Hsi MS, Tang LM, Fong VH: Epilepsy and intracranial meningiomas. Zhonghua Yi Xue Za Zhi (Taipei) 55:151-155, 1995

9. Chozick BS, Reinert SE, Greenblatt SH: Incidence of seizures after surgery for supratentorial meningiomas: a modern analysis. J Neurosurg 84:382-386, 1996

10. Cramer JA, Mintzer S, Wheless J, Mattson RH: Adverse effects of antiepileptic drugs: a brief overview of important issues. Expert Rev Neurother 10:885-891, 2010

11. de Vries J, Wakhloo AK: Cerebral oedema associated with WHO-I, WHO-II, and WHO-III-meningiomas: correlation of clinical, computed tomographic, operative and histological findings. Acta Neurochir (Wien) 125:34-40, 1993

12. Dijkstra M, van Nieuwenhuizen D, Stalpers LJ, Wumkes M, Waagemans M, Vandertop WP, et al: Late neurocognitive sequelae in patients with WHO grade I meningioma. J Neurol Neurosurg Psychiatry 80:910-915, 2009

13. Engel J, Van Ness P, Rasmussen T, Ojemann L: Outcome with respect to epileptic seizures, in Engel J (ed): Surgical Treatment of the Epilepsies, ed 2. New York: Raven Press, 1993, pp 609-621

14. Englot DJ, Berger MS, Barbaro NM, Chang EF: Factors associated with seizure freedom in the surgical resection of glioneuronal tumors. Epilepsia 53:51-57, 2012

15. Englot DJ, Berger MS, Barbaro NM, Chang EF: Predictors of seizure freedom after resection of supratentorial low-grade gliomas. A review. J Neurosurg 115:240-244, 2011

16. Englot DJ, Berger MS, Chang EF, Garcia PA: Characteristics and treatment of seizures in patients with high-grade glioma: a review. Neurosurg Clin N Am 23:227-235, viiviii, 2012

17. Englot DJ, Han SJ, Berger MS, Barbaro NM, Chang EF: Extent of surgical resection predicts seizure freedom in lowgrade temporal lobe brain tumors. Neurosurgery 70:921928, 2012

18. Fang S, Zhan Y, Xie YF, Shi Q, Dan W: Predictive value of electrocorticography for postoperative epilepsy in patients with supratentorial meningioma. J Clin Neurosci 20:112116,2013

19. Ferrante L, Acqui M, Artico M, Mastronardi L, Rocchi G, Fortuna A: Cerebral meningiomas in children. Childs Nerv Syst 5:83-86, 1989

20. Gazzeri R, Galarza M, Gazzeri G: Giant olfactory groove meningioma: ophthalmological and cognitive outcome after bifrontal microsurgical approach. Acta Neurochir (Wien) 150:1117-1126, 2008

21. Germano IM, Edwards MS, Davis RL, Schiffer D: Intracranial meningiomas of the first two decades of life. J Neurosurg 80:447-453, 1994

22. Giombini S, Solero CL, Lasio G, Morello G: Immediate and late outcome of operations for parasagittal and falx meningiomas. Report of 342 cases. Surg Neurol 21:427-435, 1984

23. Glantz MJ, Cole BF, Forsyth PA, Recht LD, Wen PY, Chamberlain MC, et al: Practice parameter: anticonvulsant prophylaxis in patients with newly diagnosed brain tumors. Report of the Quality Standards Subcommittee of the American Academy of Neurology. Neurology 54:1886-1893, 2000

24. Glantz MJ, Cole BF, Friedberg MH, Lathi E, Choy H, Furie $\mathrm{K}$, et al: A randomized, blinded, placebo-controlled trial of divalproex sodium prophylaxis in adults with newly diagnosed brain tumors. Neurology 46:985-991, 1996

25. Howng SL, Kwan AL: Intracranial meningioma. Gaoxiong Yi Xue Ke Xue Za Zhi 8:312-319, 1992

26. Im SH, Wang KC, Kim SK, Oh CW, Kim DG, Hong SK, et al: Childhood meningioma: unusual location, atypical radiological findings, and favorable treatment outcome. Childs Nerv Syst 17:656-662, 2001

27. Iwado E, Ichikawa T, Kosaka H, Otsuka S, Kambara H, Tamiya T, et al: Role of VEGF and matrix metalloproteinase-9 in peritumoral brain edema associated with supratentorial benign meningiomas. Neuropathology 32:638-646, 2012

28. Jallo GI, Benjamin V: Tuberculum sellae meningiomas: microsurgical anatomy and surgical technique. Neurosurgery 51:1432-1440, 2002

29. Kawaguchi T, Kameyama S, Tanaka R: Peritumoral edema and seizure in patients with cerebral convexity and parasagittal meningiomas. Neurol Med Chir (Tokyo) 36:568-574, 1996

30. Kilpatrick C, Kaye A, Dohrmann P, Gonzales M, Hopper J: Epilepsy and primary cerebral tumours. J Clin Neurosci 1:178-181, 1994

31. Kinoshita M, Goto T, Okita Y, Kagawa N, Kishima H, Hashimoto N, et al: Diffusion tensor-based tumor infiltration index cannot discriminate vasogenic edema from tumor-infiltrated edema. J Neurooncol 96:409-415, 2010

32. Komotar RJ, Raper DM, Starke RM, Iorgulescu JB, Gutin PH: Prophylactic antiepileptic drug therapy in patients undergoing supratentorial meningioma resection: a systematic analysis of efficacy. J Neurosurg 115:483-490, 2011

33. Kotsopoulos IA, van Merode T, Kessels FG, de Krom MC, Knottnerus JA: Systematic review and meta-analysis of incidence studies of epilepsy and unprovoked seizures. Epilepsia 43:1402-1409, 2002

34. Lambertz N, Hindy NE, Adler C, Rump K, Adamzik M, Keyvani K, et al: Expression of aquaporin 5 and the AQP5 polymorphism A(-1364)C in association with peritumoral brain edema in meningioma patients. J Neurooncol 112:297-305, 2013

35. Lee ST, Lui TN, Chang CN, Cheng WC, Wang DJ, Heimburger RF, et al: Prophylactic anticonvulsants for prevention of immediate and early postcraniotomy seizures. Surg Neurol 31:361-364, 1989

36. Li X, Zhao J: Intracranial meningiomas of childhood and adolescence: report of 34 cases with follow-up. Childs Nerv Syst 25:1411-1417, 2009

37. Lieu AS, Howng SL: Intracranial meningiomas and epilepsy: incidence, prognosis and influencing factors. Epilepsy Res 38:45-52, 2000

38. Lobato RD, Alday R, Gómez PA, Rivas JJ, Domínguez J, Cabrera A, et al: Brain oedema in patients with intracranial meningioma. Correlation between clinical, radiological, and 
histological factors and the presence and intensity of oedema. Acta Neurochir (Wien) 138:485-494, 1996

39. Mantle RE, Lach B, Delgado MR, Baeesa S, Bélanger G: Predicting the probability of meningioma recurrence based on the quantity of peritumoral brain edema on computerized tomography scanning. J Neurosurg 91:375-383, 1999

40. Meixensberger J, Meister T, Janka M, Haubitz B, Bushe KA, Roosen K: Factors influencing morbidity and mortality after cranial meningioma surgery-a multivariate analysis. Acta Neurochir Suppl 65:99-101, 1996

41. Menon G, Nair S, Sudhir J, Rao BR, Mathew A, Bahuleyan B: Childhood and adolescent meningiomas: a report of 38 cases and review of literature. Acta Neurochir (Wien) 151:239-244, 2009

42. Moher D, Liberati A, Tetzlaff J, Altman DG: Preferred reporting items for systematic reviews and meta-analyses: the PRISMA statement. PLoS Med 6:e1000097, 2009

43. Musluman AM, Yilmaz A, R TC, Cavusoglu H, Kahyaoglu O, Aydin Y: Unilateral frontal interhemispheric transfalcial approaches for the removal of olfactory groove meningiomas Turk Neurosurg 22:174-182, 2012

44. Nakasu S, Fukami T, Jito J, Matsuda M: Microscopic anatomy of the brain-meningioma interface. Brain Tumor Pathol 22:53-57, 2005

45. Nassehi D: Intracranial meningiomas, the VEGF-A pathway, and peritumoral brain oedema. Dan Med J 60:B4626, 2013

46. Ng WH, Hy JW, Tan WL, Liew D, Lim T, Ang BT, et al: Aquaporin-4 expression is increased in edematous meningiomas. J Clin Neurosci 16:441-443, 2009

47. Nordqvist AC, Smurawa H, Mathiesen T: Expression of matrix metalloproteinases 2 and 9 in meningiomas associated with different degrees of brain invasiveness and edema. $\mathbf{J}$ Neurosurg 95:839-844, 2001

48. North JB, Penhall RK, Hanieh A, Frewin DB, Taylor WB: Phenytoin and postoperative epilepsy. A double-blind study. J Neurosurg 58:672-677, 1983

49. Osawa T, Tosaka M, Nagaishi M, Yoshimoto Y: Factors affecting peritumoral brain edema in meningioma: special histological subtypes with prominently extensive edema. J Neurooncol 111:49-57, 2013

50. Pistolesi S, Fontanini G, Camacci T, De Ieso K, Boldrini L, Lupi G, et al: Meningioma-associated brain oedema: the role of angiogenic factors and pial blood supply. J Neurooncol 60:159-164, 2002

51. Ramamurthi B, Ravi B, Ramachandran V: Convulsions with meningiomas: incidence and significance. Surg Neurol 14:415-416, 1980

52. Ravindranath K, Vasudevan MC, Pande A, Symss N: Management of pediatric intracranial meningiomas: an analysis of 31 cases and review of literature. Childs Nerv Syst 29:573-582, 2013

53. Rothoerl RD, Bernreuther D, Woertgen C, Brawanski A: The value of routine electroencephalographic recordings in predicting postoperative seizures associated with meningioma surgery. Neurosurg Rev 26:108-112, 2003

54. Rudà R, Trevisan E, Soffietti R: Epilepsy and brain tumors. Curr Opin Oncol 22:611-620, 2010

55. Rushing EJ, Olsen C, Mena H, Rueda ME, Lee YS, Keating $\mathrm{RF}$, et al: Central nervous system meningiomas in the first two decades of life: a clinicopathological analysis of $87 \mathrm{pa}-$ tients. J Neurosurg 103 (6 Suppl):489-495, 2005

56. Sampson JH, Barker FG II: Methodology and reporting of meta-analyses in the neurosurgical literature. J Neurosurg 120:791-794, 2014

57. Simpson D: The recurrence of intracranial meningiomas after surgical treatment. J Neurol Neurosurg Psychiatry 20:22-39, 1957
58. Sirven JI, Wingerchuk DM, Drazkowski JF, Lyons MK, Zimmerman RS: Seizure prophylaxis in patients with brain tumors: a meta-analysis. Mayo Clin Proc 79:1489-1494, 2004

59. Sughrue ME, Cage T, Shangari G, Parsa AT, McDermott MW: Clinical characteristics and surgical outcomes of patients presenting with meningiomas arising predominantly from the floor of the middle fossa. Neurosurgery 67:80-86, 2010

60. Sughrue ME, Rutkowski MJ, Chang EF, Shangari G, Kane AJ, McDermott MW, et al: Postoperative seizures following the resection of convexity meningiomas: are prophylactic anticonvulsants indicated? Clinical article. J Neurosurg 114:705-709, 2011

61. Taphoorn MJ, Klein M: Cognitive deficits in adult patients with brain tumours. Lancet Neurol 3:159-168, 2004

62. Tsuji M, Shinomiya S, Inoue R, Sato K: Prospective study of postoperative seizure in intracranial meningioma. Jpn J Psychiatry Neurol 47:331-334, 1993

63. Tucha O, Smely C, Preier M, Becker G, Paul GM, Lange $\mathrm{KW}$ : Preoperative and postoperative cognitive functioning in patients with frontal meningiomas. J Neurosurg 98:21-31, 2003

64. Waagemans ML, van Nieuwenhuizen D, Dijkstra M, Wumkes M, Dirven CM, Leenstra S, et al: Long-term impact of cognitive deficits and epilepsy on quality of life in patients with low-grade meningiomas. Neurosurgery 69:72-79, 2011

65. Wang P, Ni RY, Chen MN, Mou KJ, Mao Q, Liu YH: Expression of aquaporin-4 in human supratentorial meningiomas with peritumoral brain edema and correlation of VEGF with edema formation. Genet Mol Res 10:2165-2171, 2011

66. Wiemels J, Wrensch M, Claus EB: Epidemiology and etiology of meningioma. J Neurooncol 99:307-314, 2010

67. Yoshioka H, Hama S, Taniguchi E, Sugiyama K, Arita K, Kurisu K: Peritumoral brain edema associated with meningioma: influence of vascular endothelial growth factor expression and vascular blood supply. Cancer 85:936-944, 1999

68. Zachenhofer I, Donat M, Oberndorfer S, Roessler K: Perioperative levetiracetam for prevention of seizures in supratentorial brain tumor surgery. J Neurooncol 101:101-106, 2011

69. Zheng Z, Chen P, Fu W, Zhu J, Zhang H, Shi J, et al: Early and late postoperative seizure outcome in 97 patients with supratentorial meningioma and preoperative seizures: a retrospective study. J Neurooncol 114:101-109, 2013

70. Zwerdling T, Dothage J: Meningiomas in children and adolescents. J Pediatr Hematol Oncol 24:199-204, 2002

\section{Disclosures}

The authors report no conflict of interest concerning the materials or methods used in this study or the findings specified in this paper.

\section{Author Contributions}

Conception and design: Englot, McDermott. Acquisition of data: Englot. Analysis and interpretation of data: Englot, Magill, Han, Berger, McDermott. Drafting the article: Englot. Critically revising the article: Magill, Han, Chang, Berger, McDermott. Reviewed submitted version of manuscript: McDermott. Approved the final version of the manuscript on behalf of all authors: Englot. Statistical analysis: Englot. Study supervision: Chang, Berger, McDermott.

\section{Correspondence}

Dario J. Englot, Department of Neurological Surgery, University of California, San Francisco, 505 Parnassus Ave., Box 0112, San Francisco, CA 94143-0112. email: englot@gmail.com. 